\title{
Analyses of winter circulation types and their impacts on haze pollution in Beijing
} He Jianjun ${ }^{1 *}$, Gong Sunling ${ }^{1}$, Zhou Chunhong ${ }^{1}$, Lu Shuhua ${ }^{1}$, Wu Lin ${ }^{2 *}$, Chen Ying ${ }^{3}$, Yu Ye ${ }^{4}$, Zhao Suping $^{4}$, Yu Lijuan ${ }^{5}$, ChengmeiYin $^{5}$

${ }^{1}$ State Key Laboratory of Severe Weather \& Key Laboratory of Atmospheric Chemistry of CMA, Chinese Academy of Meteorological Sciences, Beijing 100081, China

${ }^{2}$ The College of Environmental Science \& Engineering, Nankai University, Tianjin 300071, China

${ }^{3}$ Lancaster Environment Centre, Lancaster University, Lancaster, LA1 4YQ, UK

${ }^{4}$ Northwest Institute of Eco-Environment and Resources, Chinese Academy of Sciences, Lanzhou 730000, China

${ }^{5}$ Jinan Meteorological Bureau, Jinan 250002, China

*Correspondence to: He Jianjun (hejianjun@camscma.cn) and Wu Lin (envwu@vip.qq.com)

Abstract: For a better understand the interannual variation of winter haze pollution, this study classifies winter circulation types and investigates their impacts on local meteorology and haze pollution from 1980 to 2017 in Beijing. Circulation types are classified by T-mode principal component analysis combined with the K-means cluster method using European Centre for Mediumrange Weather Forecasts ERA-interim sea level pressure data. The results can effectively distinguish the cold air-mass processes, degeneration of cold air-mass, and stagnant weather conditions. Usually, cold air-mass process over Beijing is accompanied by a low temperature, high relative humidity, large pressure gradient and near-surface wind speed, and deep mixing layer. The cold air-mass process facilitates pollutants dispersion and transport them outside Beijing, and hence lower $\mathrm{PM}_{2.5}$ concentration and frequencies of haze events. In contrast, the local meteorology and haze pollution were almost the inverse for stagnant weather. The local meteorological conditions and haze pollution for the degeneration of cold air are between the previous circulation types. Based on $\mathrm{PM}_{2.5}$ observation during 2010-2017, the occurrence frequency of cold air was low in the recent winters of 2013, 2014 and 2017, and resulted in severe $\mathrm{PM}_{2.5}$ pollution. High frequency of stagnant weather (48.4\%) was one of the reasons that haze pollution reached 37\% during 1980-2017 over Beijing. The time series of haze frequency was negatively correlated with that of cold air frequency. During 38 
winters from 1980 to 2017, a decreased trend of haze days was found, which was partly related to an increased trend of cold air frequency. However, the trends of haze days and cold air in Beijing were not significant based on regression analysis.

Keywords: circulation types, local meteorology, haze pollution, $\mathrm{PM}_{2.5}$

\section{Introduction}

Haze is defined as large amounts of inactivated fine particles floating in the atmosphere that result in low visibility (less than $10 \mathrm{~km}$ ) and turbid air. It is a weather phenomenon and a natural weather disaster (Zhang et al., 2013). With rapid economic development, haze pollution has occurred frequently and has attracted attention from governments, the public, and researchers. Severe haze, which is mainly caused by serious aerosol pollution, is not a completely natural phenomenon in China (Zhang et al., 2013). And it also affects meteorological processes, such as precipitation (Guo et al., 2016). The formation of haze decreases atmospheric visibility, affects the production and daily live, and has an adverse impact on human health (An et al., 2015). Unfortunately, at least $30 \%$ of the area and nearby 800 million people in China are affected by different degrees of haze (Che et al., 2009). There were relatively few annual haze days in the 1960s, but they increased sharply in the 1970s, remained stable to 1995, and then increased from 1995 to 2012 in North China Plain (Chen et al., 2015). Understanding the formation mechanisms of haze is very important for haze prevention.

Pollutant emission and meteorological conditions are two key factors for haze pollution, and high pollutant emission is the primary cause. According to the China Statistical Yearbook, the emission of sulfur dioxide, nitric oxide and dust reached $1.86 \times 10^{7}, 1.85 \times 10^{7}$, and $1.54 \times 10^{7}$ tons, respectively, in 2015 (http://www.stats.gov.cn/tjsj/ndsj/2016/indexch.htm). Meteorological condition is another important factor for haze pollution. Meteorological parameters, such as temperature, relative humidity, wind speed, and boundary layer height, are significantly correlated with pollutant concentrations in most Chinese cities and explained more than $70 \%$ of the variance of daily average pollutant concentrations (He et al., 2017a). In January 2013, a persistent severe haze event occurred over eastern China. Unusual meteorological conditions were responsible for this persistent severe haze event (Zhang et al., 2014). The long term trend of haze is regional and seasonal dependent. Haze showed decreasing trends during 30 winters from 1981 to 2010, while summertime haze displayed 
continuous increasing trends, and obvious regional difference of haze trends was detected in southern Hebei province (Fu et al., 2014). The weakening of near-surface winds during 1985-2005 caused the increase in winter haze days over eastern China (Yang et al., 2016). At different spatial scales, meteorological conditions can be divided into a large-scale circulation type and local meteorological conditions. The circulation type governs local meteorological conditions and is effective in the identification of haze pollution (Oanh et al., 2005); it is the main factor driving the day-to-day variations in pollutant concentrations (Lee et al., 2012). Although many studies have investigated the relation between circulation type and haze pollution (or air quality) (Demuzere et al., 2009; He et al., 2016a; He et al., 2017a; Jiang et al., 2014; Jiang et al., 2016; Lee et al., 2012; Oanh et al., 2005; Pearce et al., 2011; Zhang et al., 2012), this relation can also vary with time, location and pollutants (Jiang et al., 2017).

Beijing, as the capital of China, has frequently suffered severe haze pollution in winter. Many pollutant emission sources surround Beijing, and local vehicle emissions, special terrain and meteorological conditions are the main reasons for haze pollution in Beijing (He et al., 2016b). Horizontal transport of pollutants, which is affected by atmospheric circulation, may be the most important factor determining the air quality of Beijing (Miao et al., 2017). Some studies have focused on the relation between circulation types and air pollution in Beijing and the surrounding region (Chen et al., 2008; Chen et al., 2009; Li et al., 2012; Meng and Cheng, 2002; Miao et al., 2017; Zhang et al., 2012). However, few studies have analysed the long-term winter circulation types by using an objective method and investigated their relationships with haze pollution in Beijing and surrounding regions. This article extends our previous work (He et al., 2017b) by using long-term data to investigate the thermal and dynamical characteristics of circulation types and their impacts on local meteorological conditions and haze pollution over Beijing. Because haze pollution is most severe in winter, this paper focuses on the winter circulation type. This result can help us understand the development of haze events and is useful for haze forecasting and prevention over Beijing and similar areas.

\section{Data and method}

\subsection{Meteorological data}

The European Centre for Medium-range Weather Forecasts (ECMWF) ERA-interim reanalysis 
data (https://www.ecmwf.int/en/research/climate-reanalysis/era-interim) for 38 winters (December to February) from 1980 to 2017 were used in this study. The spatial and temporal resolutions of ECMWF ERA-interim data are $0.25^{\circ}$ and 6 hours (i.e., 08:00, 14:00, 20:00, 02:00 local standard time every day), respectively. Sea Level Pressure (SLP) for the area of $110^{\circ} \mathrm{E}-125^{\circ} \mathrm{E} / 35^{\circ} \mathrm{N}-45^{\circ} \mathrm{N}$ was used to identify circulation type following previous studies (He et al., 2017b; Jiang et al., 2017; Zhang et al., 2012). Temperature and dew point temperature at $850 \mathrm{hPa}, 700 \mathrm{hPa}$, and $500 \mathrm{hPa}$ from the ECMWF ERA-interim reanalysis data were used to calculate the $\mathrm{K}$ index, which represents atmospheric thermal unstable capacity in the middle-low troposphere (Zhang et al., 2014). The equation for the K index is given in following:

$$
\mathrm{K}=\left(T_{850}-T_{500}\right)+T_{d 850}-\left(T_{700}-T_{d 700}\right)
$$

where $\mathrm{K}$ is the $\mathrm{K}$ index and $T_{850}, T_{700}$, and $T_{500}$ are temperatures at $850 \mathrm{hPa}, 700 \mathrm{hPa}$, and 500 $\mathrm{hPa}$, respectively. $T_{d 850}$ and $T_{d 700}$ are the dew point temperatures at $850 \mathrm{hPa}$ and $700 \mathrm{hPa}$, respectively. According to the definition of the $\mathrm{K}$ index, a larger $\mathrm{K}$ index represents a more unstable middle-low tropospheric atmosphere.

Near-surface daily climatological data (including daily average temperature, relative humidity, wind speed and wind direction) during 38 winters from 1980 to 2017 at Beijing station were acquired from the National Meteorological Information Center (http://data.cma.cn/site/index.html). These datasets were used to construct a relation between circulation type and local meteorological conditions. The location of Beijing station is shown in Figure 1.

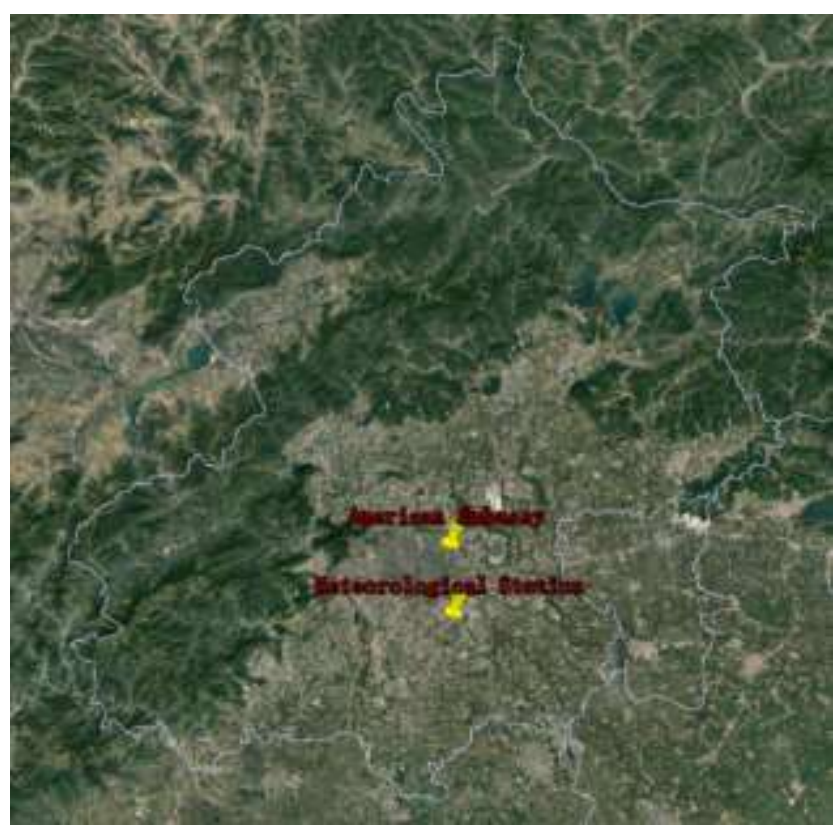

Figure 1. The location of air quality monitoring stations (American Embassy) and meteorological 
station.

\subsection{Air quality data}

Haze is mainly caused by aerosol pollution (Zhang et al., 2013). A new 'Ambient air quality standard' was published in 2012 by the Ministry of Environmental Protection and the General Administration of Quality Supervision, Inspection and Quarantine of China. Particulate matter with aerodynamic diameter less than $2.5 \mu \mathrm{m}\left(\mathrm{PM}_{2.5}\right)$ was introduced in the air quality index system for the first time in China. However, long-term continuous observation of $\mathrm{PM}_{2.5}$ is few in China. $\mathrm{PM}_{2.5}$ concentration was observed and released (http://www.stateair.net/web/post/1/1.html) since 2008 in American Embassy in Beijing (Figure 1). The monitoring station represents urban-traffic type in Beijing. Considering data integrity, $\mathrm{PM}_{2.5}$ concentrations in American Embassy during 8 winters from 2010 to 2017 were used to analyze the impact of circulation type on aerosol concentration. The data quality control method for $\mathrm{PM}_{2.5}$ concentration is described in our previous study (He et al., 2017a).

\subsection{Haze days}

With an increase in humidity, hygroscopic growth occurs on fine particles, which then activate as cloud condensation nuclei and finally convert haze to fog. Visibility, particulate matter and relative humidity are thus three important properties of haze. Because of the absence of long-term particulate matter observation, only days with visibility less than $10 \mathrm{~km}$ and relative humidity less than $90 \%$ are defined as haze days based on previous studies (Yang et al., 2016). Based on visibility and relative humidity, winter haze days from 1980 to 2017 at Beijing station were obtained from the National Meteorological Information Centre.

Aerosol scattering and absorption of visible light deteriorate atmospheric visibility. Haze pollution is closely related to the loading of aerosol. Time series of average $\mathrm{PM}_{2.5}$ concentration and occurrence frequency of haze days are shown in Figure 2. Relatively low $\mathrm{PM}_{2.5}$ concentration accompany with a high occurrence frequency of haze is observed in 2015 and 2016. The possible reason maybe the change of relative humidity or chemical components of $\mathrm{PM}_{2.5}$ which affects optical characteristics of aerosol. 


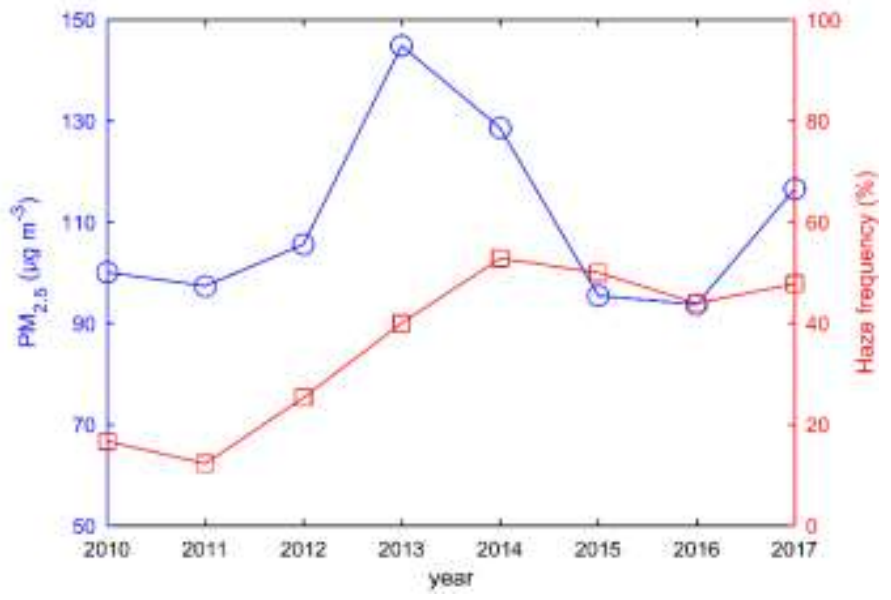

Figure 2. Time series of average $\mathrm{PM}_{2.5}$ concentration and occurrence frequency of haze days during 8 winters from 2010 to 2017.

\subsection{Circulation types}

Five main circulation classification techniques, namely the correlation method, cluster analysis, principal component analysis (PCA), the fuzzy method, and nonlinear methods, have been frequently used to classify circulation types (Zhang et al., 2012). In this study, T-mode PCA combined with Kmeans cluster is used, because previous researchers have proposed this is the best approach for revealing data structures and effectively identifying circulation types (Huth, 1996). And this method has been widely used in previous studies in China (He et al., 2016a; He et al., 2017a; He et al., 2017b; Miao et al., 2017; Zhang et al., 2012). Data processing to determine circulation type included five steps. First, three-dimensional ERA SLP grid data (longitude $\times$ latitude $\times$ time) was reshaped to twodimensional data (grid $\times$ time). Second, data was normalized using z-scores method. Third, the normalized data performed PCA. Fourth, main components were acquired according to the cumulative variance contribution of $85 \%$. Fifth, the main components were clustered using the Kmeans cluster, and synoptic-scale circulations were ascertained based on cluster results. The number of clusters depends on the criterion function (Liu and Gao, 2011), and the inflection of the criterion function represents the optimal number of clusters. Finally, six circulation types were determined (i.e., CT1 to CT6). The weather and diffusion characteristics of six circulations are discussed in the following. 


\section{Results and Discussion}

\subsection{Circulation types and weather characteristics}

Winter climate characteristics in North China are closely related to the winter monsoon. Previous studies have revealed that a strong winter monsoon is beneficial to pollutant dispersion over Beijing and surrounding regions (Liu et al., 2017). The change of winter circulation types is a direct indicator of winter monsoon intensity. Using the T-mode PCA combined with the K-means cluster, six circulation types are identified. The meteorological fields at each moment are assigned to one circulation type. The mean meteorological fields for six circulation types are calculated. Figure 3 shows the mean SLP of six circulation types. According to the spatial distribution of SLP, CT4 showed the strongest cold air synoptic process in North China, with a cold high pressure that reached 1040 $\mathrm{hPa}$ and covered Inner Mongolia. Figure 4 shows the spatial distribution of meteorological fields for six circulation types at $1000 \mathrm{hPa}$. Most parts of North China were controlled by north winds for CT4. The bottom of high pressure formed an obvious anti-cyclone. A southwest-northeast dry belt was located in the centre of North China and the temperature gradient was large. Low temperature, low relative humidity, and high wind speed were typical weather characteristics over Beijing for the CT4 circulation type. The cold air synoptic process of CT5 was weaker than that of CT4. Compared with CT4, similar weather characteristics for CT5 were found in North China (Figure 3). CT3 was a degeneration of cold air in North China. The pressure gradient of CT3 was significantly smaller than that of CT4 and CT5. Although the meteorological pattern was similar to that of CT4 and CT5, the wind speed (temperature) decreased (increased) remarkably over Beijing. With small pressure gradients, CT1, CT2 and CT6 are typical stagnant weather. For CT1, Beijing was in the rear of a weak high-pressure system. Most parts of North China were controlled by southern and southwestern wind. The temperature and humidity in Beijing and surrounding regions were affected by warm advection and water vapour transport were relatively high. For CT2, weak northwest wind covered most parts of North China. Wind decreases significantly from northwest to southeast of North China. Spatial distribution of wind was unfavourable for the ventilation capacity over Beijing. For CT6, a weak lowpressure system existed in Northeast China, and the pressure gradient was very weak in North China. Affected by surface pressure, the northwest region of Beijing was covered by western wind, whereas the southeast region to Beijing was covered by southwest wind. The change of the wind field formed 
a convergence zone. Atmospheric block resulted in low wind speed over Beijing. Temperatures were high over Beijing because of warm advection (Figure 4). Based on characteristics of meteorological fields over Beijing and surrounding areas, CT4 and CT5 can be defined as the cold air process, CT3 is defined as weak or degenerate cold air, CT1, CT2 and CT6 are defined as stagnant weather.
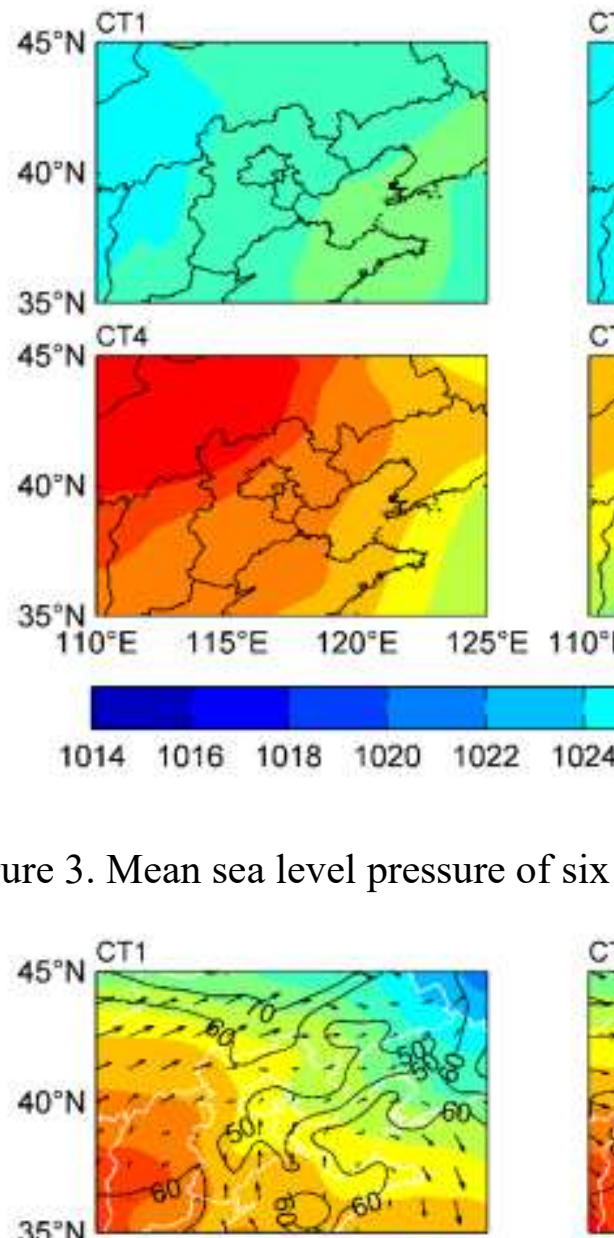

$$
{ }^{35 \mathrm{~N}}
$$$$
{ }_{150} \mathrm{coth}^{\mathrm{ch}}
$$
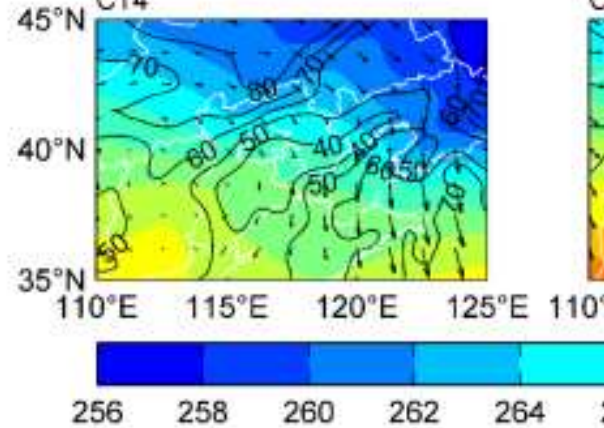

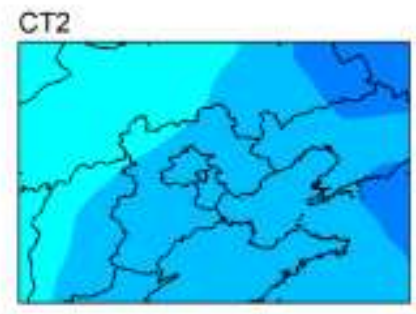

CT5
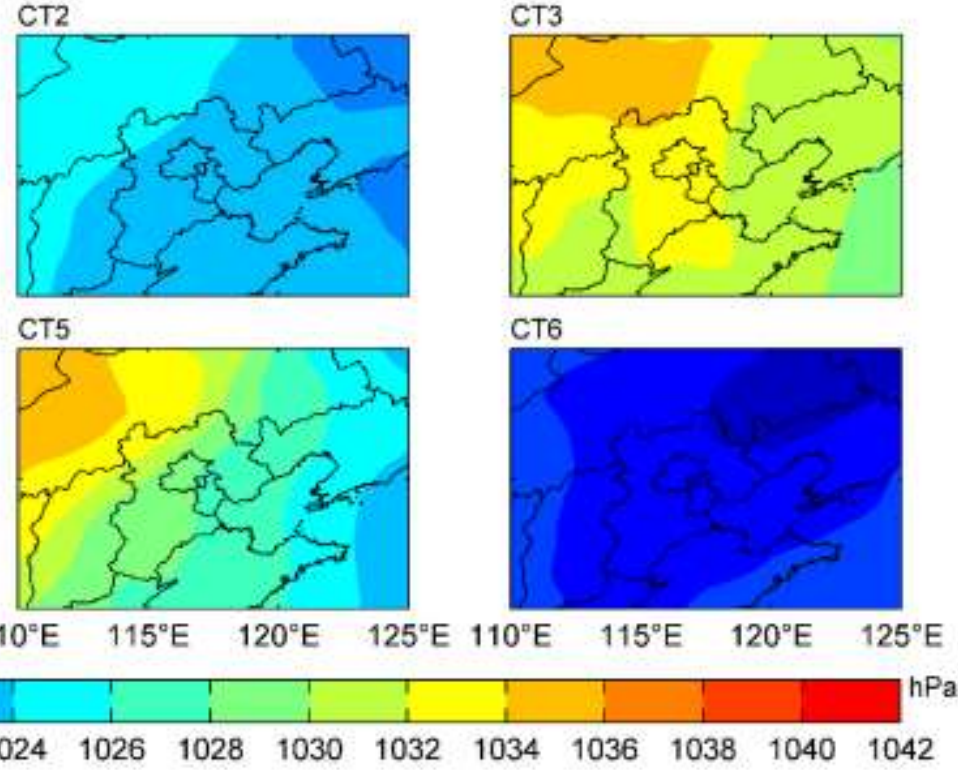

Figure 3. Mean sea level pressure of six circulation types during 38 winters from 1980 to 2017.
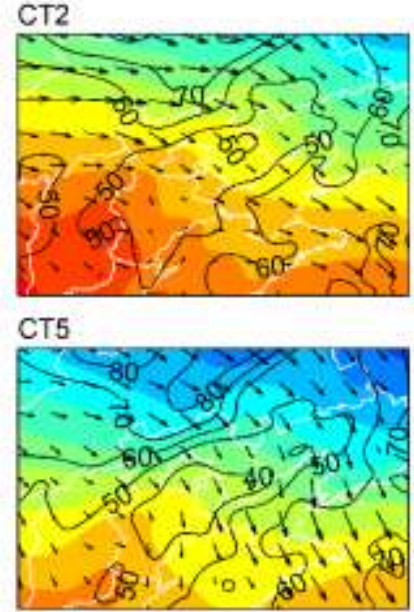

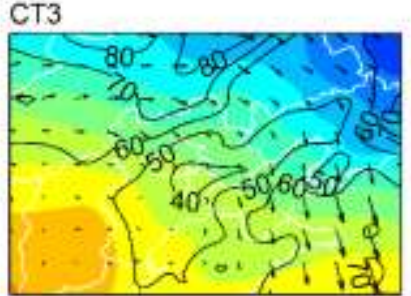

CT6
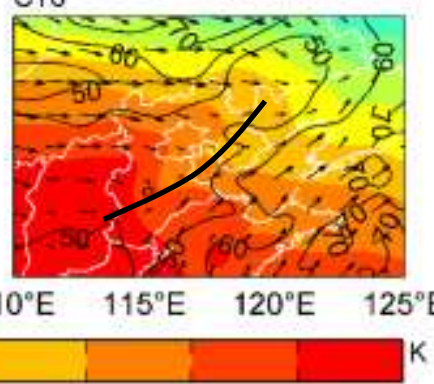

Figure 4. Mean temperature (shade), relative humidity (contour line), and wind field (arrow) of six circulation types at $1000 \mathrm{hPa}$ during 38 winters from 1980 to 2017. Black lines represent convergence lines.

Based on statistical analysis, the occurrence frequencies for CT1 to CT6 were $16.5 \%, 19.1 \%$, 
$20.7 \%, 14.3 \%, 16.6 \%$, and $12.8 \%$, respectively. The occurrence frequency of stagnant weather (CT1, CT2 and CT6) reached $48.4 \%$, and $30.9 \%$ for the cold air process (CT4 and CT5), which is conducive to ventilation. The cold air process often occurred in night and morning (02:00 and 08:00, Beijing Time). The evolution of circulation types is an important issue, and there is an evolution between the cold air process and stagnant weather in North China. When cold air breaks out, the circulation type is CT4 or CT5. With the movement of cold air from the northwest to the southeast, cold air degenerates and the circulation type becomes CT3, followed by CT1, and CT2. After a period of cold air accumulation over Siberia and Outer Mongolia, a new cold air process breaks out, and the circulation type changes from CT2 to CT4 or CT5. Another evolution between CT2 and CT6 was found.

Local meteorological conditions were closely related to synoptic scale circulation types and underlying surface condition. Figure 5 shows the box graph of surface meteorological parameters at the Beijing meteorological station (Figure 1) for six circulation types during 38 winters from 1980 to 2017. To be consistent with daily average surface meteorological parameters, a circulation type for one day is defined as a type that appears twice a day or more at four times $(08: 00,14: 00,20: 00$, and 02:00) a day. Circulation types governed local surface meteorological parameters, and meteorological parameters had significant differences for different circulation types based on variance analysis at the 95\% confidence level. The source of cold high pressure was in Outer Mongolia and Siberia. The cold air process brought a significant decrease of temperature and humidity over Beijing. According to geostrophic wind theory, wind speed is positively correlated with the pressure gradient. The cold air process resulted in a large pressure gradient and brought large winds over Beijing. The predominant direction in surface was north and northwest wind for CT4 and CT5 respectively (Figure 6). Winter cold high pressure in East Asia is a relatively shallow weather system, and the average thickness of cold high pressure is no more than $3 \mathrm{~km}$. The cold air process decreased low level temperature and the $\mathrm{K}$ index and resulted in stable atmospheric stratification in the middle-low troposphere (upper boundary layer). For stagnant weather, the local meteorological parameters were contrary to those for the cold air process, i.e., 2-m temperature, 2-m relative humidity and $\mathrm{K}$ index were large, whereas the 10-m wind speed was small in Beijing. The predominant direction in surface was southwest wind (Figure 6). Northwest wind was a second prevailing wind for CT2 and CT6. It is interesting that atmospheric stratification in the middle-low troposphere was more stable for the cold air process than 
225 for stagnant weather based on the comparison of the $\mathrm{K}$ index. For degeneration of cold air, the local 226 meteorological parameters were between the cold air and stagnant weather. North, northeast, and 227 southwest wind were the main wind direction in surface for CT3 (Figure 6).
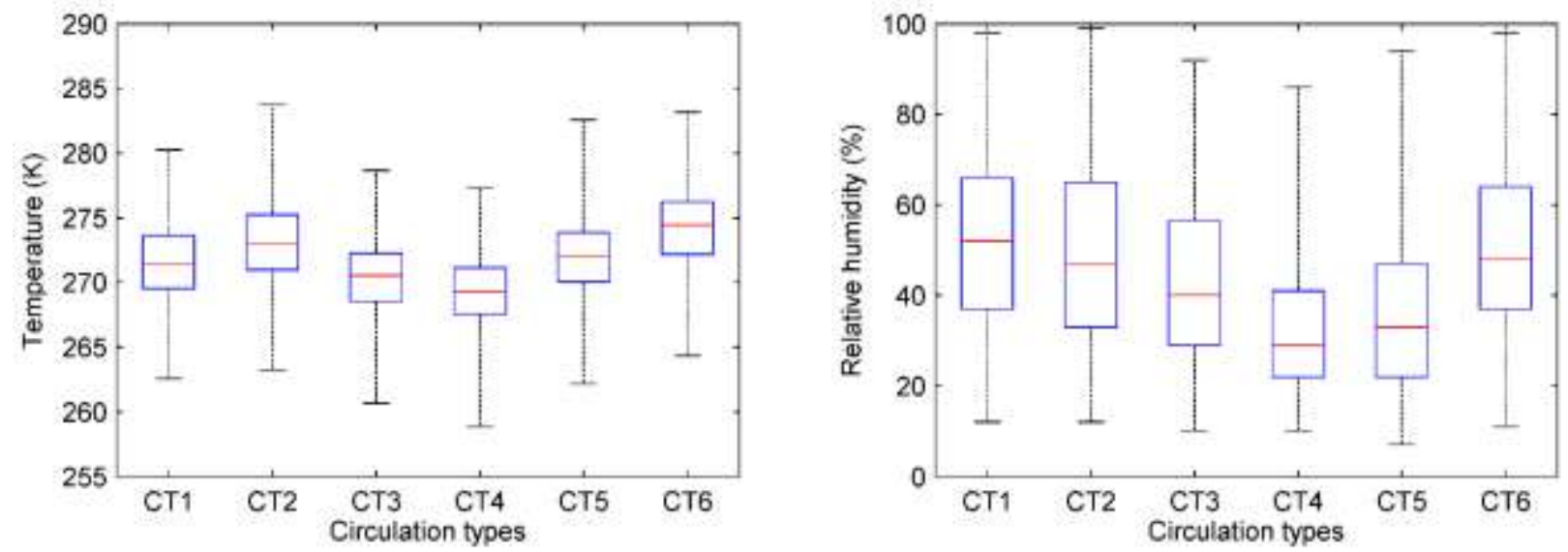

228
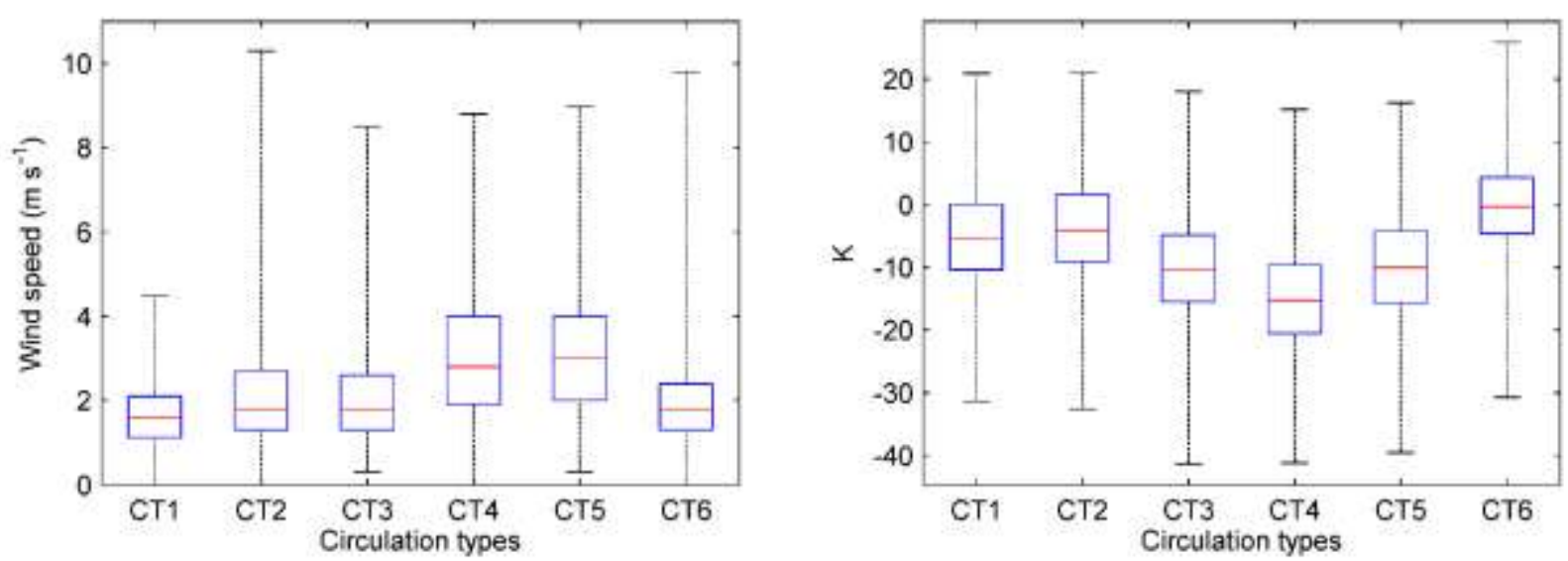

229

Figure 5. Box graph of surface pressure (a), 2-m temperature (b), 2-m relative humidity (c) and 10-m wind speed (d) in Beijing for six circulation types during 38 winters from 1980 to 2017. 


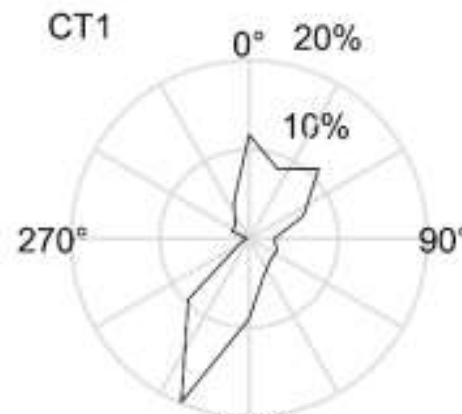

$180^{\circ}$

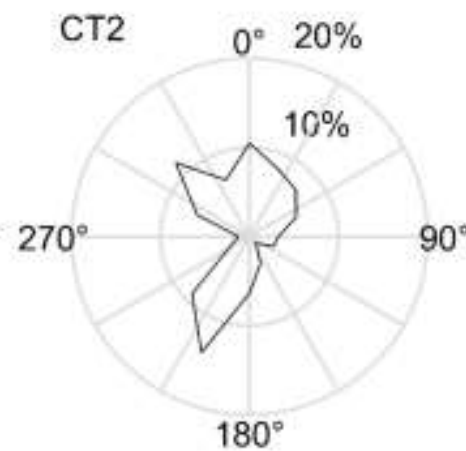

$180^{\circ}$

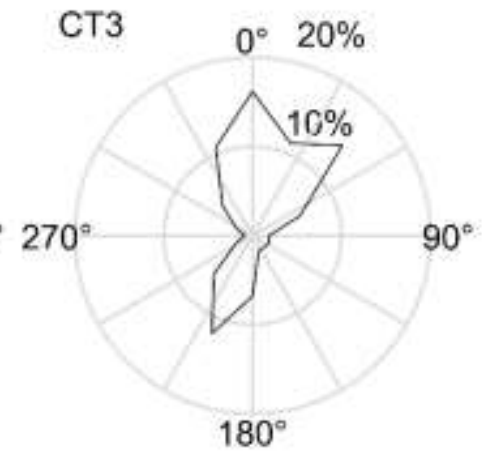

$180^{\circ}$

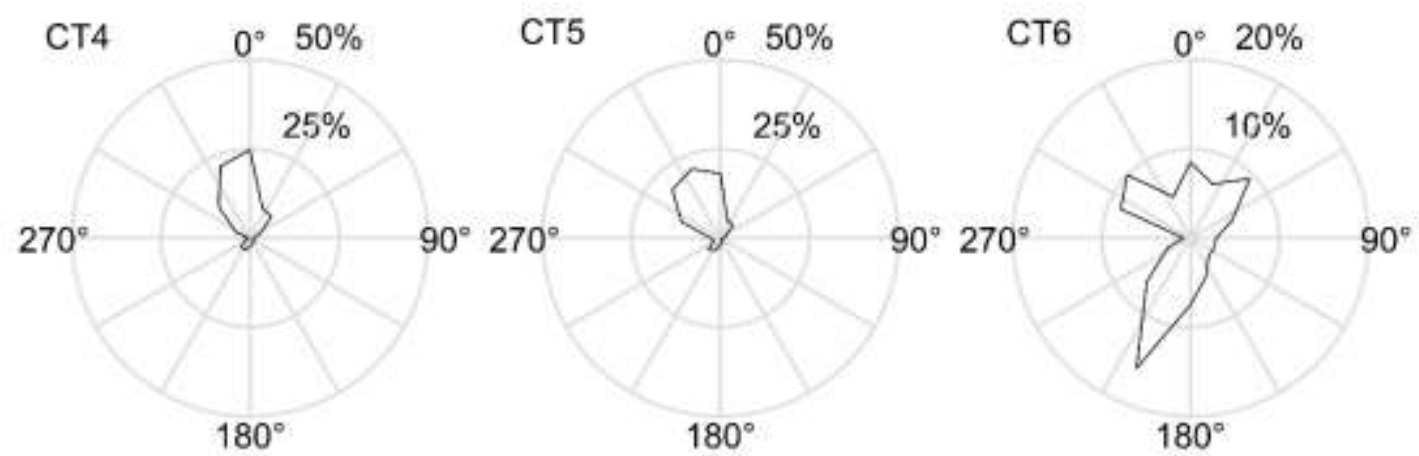

Figure 6. Wind rose map in Beijing for six circulation types during 38 winters from 1980 to 2017.

Boundary layer structures are also governed by atmospheric circulation (Miao et al., 2017). Figure

7 shows vertical profiles of potential temperature and wind speed anomaly for six circulation types.

A cold bias of potential temperature was detected for CT4 and CT5. Cold bias increased with height for CT4 and CT5, which implies that the cold air process increased the atmospheric temperature lapse rate and turbulent mixing in the boundary layer by a thermal process and formed a deep mixing layer. A positive bias of wind speed was detected for CT4 and CT5, and the positive bias increased with height in the boundary layer. This characteristic of vertical profiles of wind speed anomaly for CT4 and CT5 resulted in an increase of vertical wind shear and formed a deep mixing layer by dynamical processes. For stagnant weather, i.e., CT1, CT2, and CT6, an opposite change of the vertical profiles of potential temperature and wind speed anomaly was found and formed a shallow mixing layer by thermal and dynamical processes compared with the cold air process (CT4 and CT5). For CT3, potential temperature and wind speed were smaller than the average climatological values in the boundary layer. The bias of potential temperature was constant at different heights, whereas the 
negative bias of wind speed increased with height, which restrained the development of turbulence by dynamical processes. In general, the cold air process (stagnant weather) formed a deep (shallow) mixing layer by affecting local atmospheric thermal and dynamical processes. These results did not contradict the $\mathrm{K}$ index because of different atmospheric height levels.
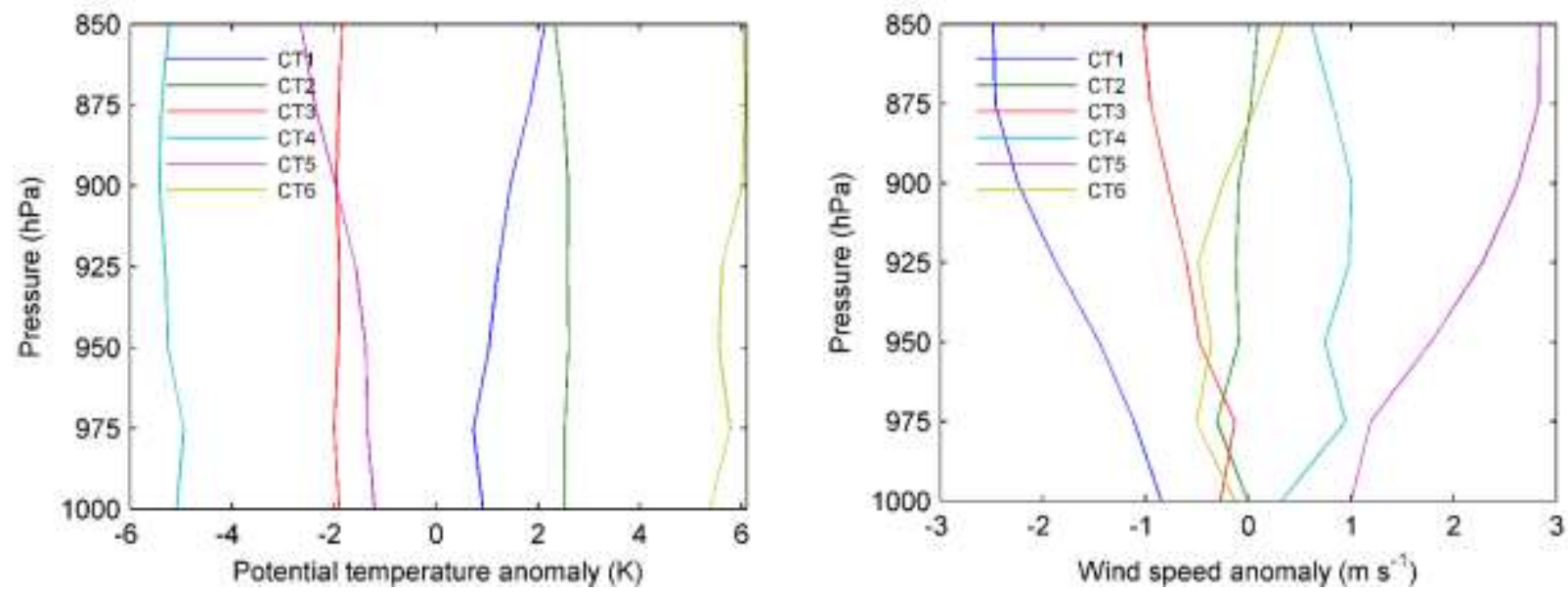

Figure 7. Vertical profiles of potential temperature anomaly (a) and wind speed anomaly (b) in Beijing for six circulation types during 38 winters from 1980 to 2017.

\subsection{Impact of weather type on $\mathrm{PM}_{2.5}$ and haze pollution}

Atmospheric circulation had an obvious impact on near-surface $\mathrm{PM}_{2.5}$ concentration (Figure 8a). Variance analysis revealed that the different circulation types had significant differences in $\mathrm{PM}_{2.5}$ concentration at the $95 \%$ confidence level. Previous studies revealed that $\mathrm{PM}_{2.5}$ concentration was positively correlated with 2-m temperature and 2-m relative humidity and was negatively correlated with 10-m wind speed over the North China Plain; the correlation passed the t-test at a $95 \%$ confidence level (He et al., 2017a; He et al., 2017b; Liu et al., 2017). With low temperature, low relative humidity, and high wind speed, the cold air process (CT4 and CT5) was favourable for pollutant dispersion and brought low $\mathrm{PM}_{2.5}$ concentration. After the cold air process (CT3), the atmospheric dispersion capability weakened, and pollutant accumulation resulted in the increase of $\mathrm{PM}_{2.5}$ concentration. Stagnant weather (CT1, CT2 and CT6) was accompanied by high temperature, high humidity and low wind speed, which was unfavourable for pollutant dispersion. For CT1, southwestern wind transported pollutants from south of Hebei province (He et al., 2017c; Miao et al., 2017) and exacerbated atmospheric pollution over Beijing. A convergence near Beijing for CT6 formed pollutant accumulation. Additionally, the atmospheric stratification in the middle-low troposphere was unstable for stagnant weather (i.e., large $\mathrm{K}$ index). Unstable atmospheric 
stratification favours the formation of cloudy and rainy weather accompanied by high humidity and is conducive to aerosol hygroscopic growth (Zhang et al., 2014). The aerosols in the middle-low troposphere decreased near-surface shortwave radiation and then restrained turbulence development. Mixing layer height is another important factor that affects air pollution (He et al., 2017a). The cold air process (stagnant weather) formed a deep (shallow) mixing layer and enhanced (weakened) the vertical mixing of pollutants, accompanied by low (high) $\mathrm{PM}_{2.5}$ concentration.
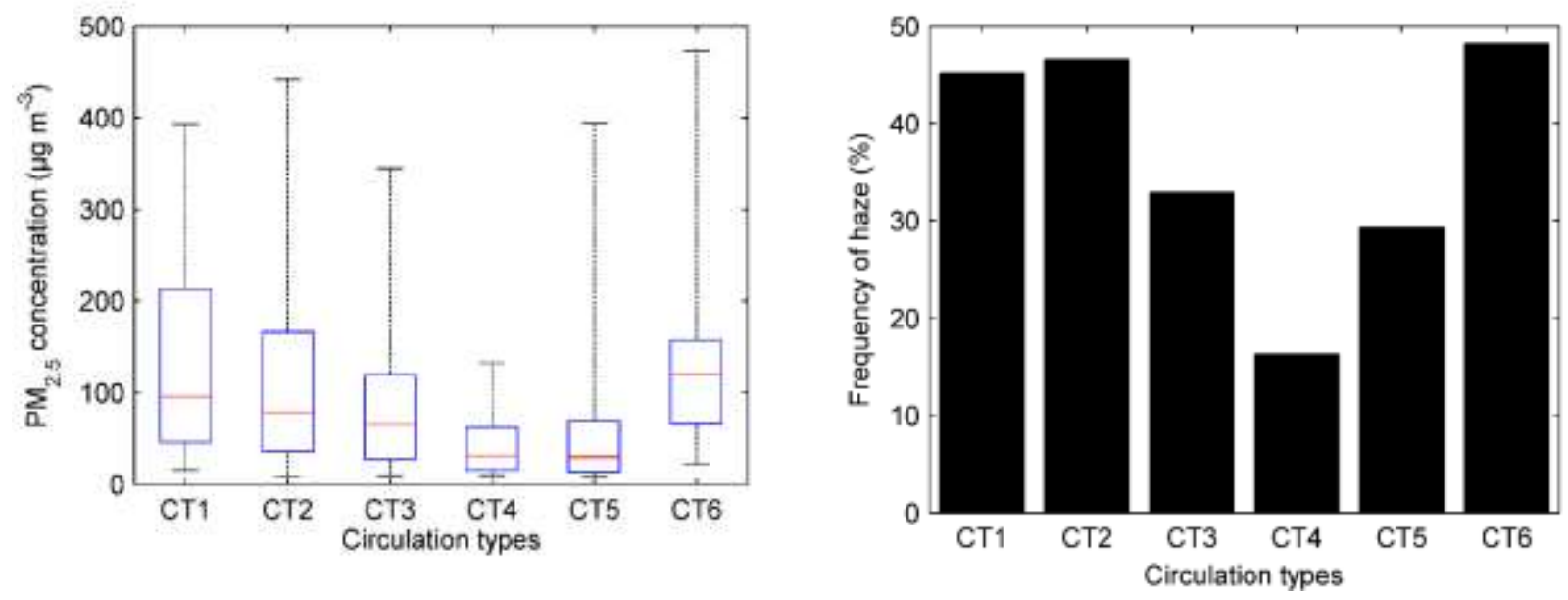

Figure 8. Box graph of daily mean $\mathrm{PM}_{2.5}$ concentration (a) during 4 winters from 2010 to 2017 and occurrence frequency of haze days (b) during 38 winters from 1980 to 2017 for six circulation types.

Table 1 shows the average $\mathrm{PM}_{2.5}$ concentration and occurrence frequency of cold air for each winter from 2010 to 2017. The Chinese Ambient Air Quality Standards (CAAQS) Grade II standards of annual mean $\mathrm{PM}_{2.5}$ concentration is $35 \mu \mathrm{g} \mathrm{m}^{-3}$. The mean $\mathrm{PM}_{2.5}$ concentration in 8 winters in Beijing is 3.2 times of the Grade II value, which implies severe air pollution due to large amount of pollutant emissions. The correlation coefficients between winter average $\mathrm{PM}_{2.5}$ concentration and occurrence frequency of six circulation types and cold air are $0.85,0.71,0.14,-0.41,-0.67,-0.37$, and -0.65 , respectively. Based on t-test, the correlation coefficients are significant for CT1, CT2 and CT5 at 95\% confidence interval. The frequency of cold air was only $25 \%, 21 \%$ and $23 \%$ in the winters of 2013 , 2014 and 2017, and a stagnant circulation of CT1 exceeded 20\% in winter 2013 and 2017, which was adverse for $\mathrm{PM}_{2.5}$ transport and dispersion to the outside and facilitated the accumulation of pollutants. The average $\mathrm{PM}_{2.5}$ concentration reaches $145 \mu \mathrm{g} \mathrm{m}^{-3}, 129 \mu \mathrm{g} \mathrm{m}^{-3}$, and $117 \mu \mathrm{g} \mathrm{m}^{-3}$ in winter 2013, 2014 and 2017. Although the frequencies of cold air and stagnant weather in winter 2017 are close to that in winter 2013, the $\mathrm{PM}_{2.5}$ concentration is significant low in winter 2017 due to great emission 
293 control measures. The frequency of cold air reached 41\% in the winters of 2012 and 2016. Although 294 the atmospheric circulation was favourable for pollutant dispersion, the average $\mathrm{PM}_{2.5}$ concentration 295 still reached $106 \mu \mathrm{g} \mathrm{m}^{-3}$ and $94 \mu \mathrm{g} \mathrm{m}^{-3}$ in the winters of 2012 and 2016, respectively, which indicates 296 that air pollution is very serious in Beijing. Large amounts of pollutant emissions are the main reason 297 for serious air pollution in the studied area (He et al., 2017a).

299 Table 1. $\mathrm{PM}_{2.5}$ concentration (mean and standard deviation, $\mu \mathrm{g} \mathrm{m}^{-3}$ ) and occurrence frequency of 300 circulation type (\%) for each winter from 2010 to 2017.

\begin{tabular}{|c|c|c|c|c|c|c|c|c|}
\hline & 2010 & 2011 & 2012 & 2013 & 2014 & 2015 & 2016 & 2017 \\
\hline $\begin{array}{l}\mathrm{PM}_{2.5} \\
\text { concentration }\end{array}$ & $100 \pm 74$ & $97 \pm 103$ & $106 \pm 90$ & $\begin{array}{l}145 \pm 11 \\
7\end{array}$ & $\begin{array}{l}129 \pm 10 \\
7\end{array}$ & $95 \pm 79$ & $94 \pm 106$ & $\begin{array}{l}117 \pm 10 \\
8\end{array}$ \\
\hline Frequency of & & & & & & & & \\
\hline CT1 & 15 & 10 & 12 & 29 & 16 & 14 & 13 & 22 \\
\hline Frequency of & & & & & & & & \\
\hline $\mathrm{CT} 2$ & 18 & 16 & 16 & 20 & 19 & 15 & 16 & 23 \\
\hline Frequency of & & & & & & & & \\
\hline $\mathrm{CT} 3$ & 20 & 13 & 27 & 18 & 27 & 23 & 20 & 25 \\
\hline Frequency of & & & & & & & & \\
\hline CT4 & 13 & 21 & 22 & 11 & 11 & 9 & 18 & 8 \\
\hline Frequency of & & & & & & & & \\
\hline CT5 & 15 & 14 & 19 & 14 & 9 & 21 & 23 & 15 \\
\hline Frequency of & & & & & & & & \\
\hline CT6 & 20 & 25 & 4 & 8 & 17 & 17 & 10 & 8 \\
\hline $\begin{array}{l}\text { Frequency of cold } \\
\text { air }\end{array}$ & 27 & 35 & 41 & 25 & 21 & 30 & 41 & 23 \\
\hline
\end{tabular}

Correlated with aerosols and visibility, haze is disastrous weather. Similar to the $\mathrm{PM}_{2.5}$ analysed 303 above, haze pollution is closely affected by atmospheric circulation (Fig. 6b). A low frequency of haze days was found under cold air processes (i.e., CT4 and CT5), and a high frequency was found 
for stagnant weather. Figure 9 shows time series of frequency of haze days and cold air. The average occurrence frequency of haze days for the 38 winters was 37\%, with a maximum value of $69 \%$ (1990) and a minimum value of $12 \%$ (1996). The correlation coefficient between the time series of frequency of haze days and cold air frequency during the 38 winters reached $-0.41(\mathrm{p}<0.1)$, which implies that the interannual variation of haze days was closely related to the interannual variation of cold air. In some extreme winters, such as those in 1996, 2008, and 2012, strong cold air improved air quality and decreased the frequency of haze days. Linear regression analysis revealed that frequency of winter haze decreased from 1980 to 2017, whereas the frequency of cold air slightly increased. The decreased trend of haze may have been partly caused by the increased trend of cold air. However, the trend of interannual variation of winter haze and cold air was not significant at the $95 \%$ confidence level. Artificial measurement of atmospheric visibility has been progressively replaced by automatic measurement since 2011. The bias between artificial measurement and automatic measurement of atmospheric visibility has introduced some uncertainty for haze pollution. Yang et al. (2016) investigated winter haze over eastern China from 1980 to 2014 and found that haze days increased from 21 days in 1980 to 42 days in 2014. The annual haze increased from 1995 to 2012 in North China (Chen et al., 2015). The trend of haze days in this paper is different from those in Yang et al. (2016) and Chen et al. (2015), partly because of the different study areas and seasons considered. Significant regional difference of the trends of haze days was also detected in Hebei province (Fu et al., 2014). And the trends of haze pollution was different from nearby Hebei province, which implies that haze pollution and interannual trends have obvious local characteristics due to local meteorology and local emissions.

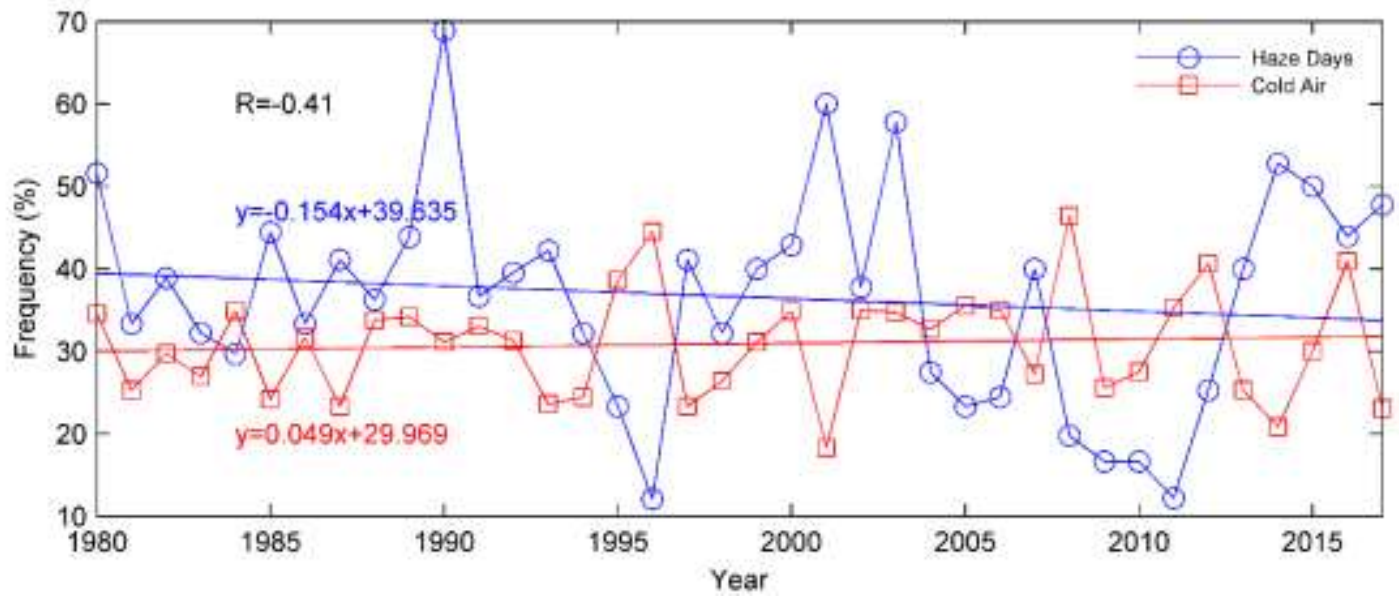

Figure 9. Time series of occurrence frequency of haze days and cold air during 38 winters from 1980 
to 2017. The blue and red lines represent the liner regression trend for haze days and cold air, respectively.

\section{Conclusion}

Pollutant emissions and meteorological conditions are two key factors that determine haze pollution. Synoptic scale atmospheric circulation governs local meteorological values and the boundary layer and thus affects local air quality. Using observations of $\mathrm{PM}_{2.5}$ concentrations, haze days based on visibility and relative humidity, meteorological observations and reanalysis data, this paper investigated winter atmospheric circulation types, and their relationship with local meteorological conditions and haze pollution over Beijing.

Six circulation types were identified that could significantly distinguish the cold air process (a degeneration of cold air) and stagnant weather. The evolution of atmospheric circulation is also analysed. For the cold air process, a large pressure gradient was found in North China with cold high pressure located over northwest of North China, accompanied by low temperature, high relative humidity, and large winds over Beijing. Temperatures and wind speed anomalies for cold air in the boundary layer implied that strong turbulence triggered by thermal and dynamical processes formed a deep mixing layer. However, the analysis of the $\mathrm{K}$ index revealed that stable atmospheric stratification in the middle-low troposphere (the upper boundary layer) was detected for the cold air process. Cold air facilitated pollutant dispersion and transport to the outside, and then lower $\mathrm{PM}_{2.5}$ concentration and frequency of haze days. The pressure gradient was very small in North China for stagnant weather, resulting in a calm weather condition with relatively high temperature, low relative humidity, low near-surface wind speed, and shallow mixing layer depth. Based on an analysis of the $\mathrm{K}$ index, atmospheric stratification was unstable in the middle-low troposphere (the upper boundary layer) compared with the cold air process. A convergence line was found surrounding Beijing surface layer, and southerly winds brought pollutants from Hebei province. Stagnant weather was adverse for pollutant dispersion and transport and facilitated the accumulation of pollution in Beijing. For the degeneration of cold air, the local meteorological conditions and haze pollution were between those of previous circulation types.

The interannual variations of $\mathrm{PM}_{2.5}$ concentration and haze days were significantly affected by the variation of atmospheric circulation. $\mathrm{PM}_{2.5}$ observations revealed that $\mathrm{PM}_{2.5}$ pollution was severe in 
the winters of 2013, 2014 and 2017, which was caused by low frequency of cold air and high frequency of stagnant weather. The average occurrence frequency of haze days for the 38 winters reached $37 \%$. The high frequency of stagnant weather $(48.4 \%)$ was one of the reason for the haze pollution. The frequency of haze days was negatively correlated with the frequency of cold air, with a correlation coefficient of $-0.41(\mathrm{p}<0.1)$. Vice versa, a decreased trend of haze days during winter from 1980 to 2017 was partly related to an increased trend of cold air frequency. However, these trends were not significant based on regression analysis.

Acknowledgements: This work was supported by the National Natural Science Foundation of China (No. 41705080 and 91544232), CAMS Basis Research Project (No. 2017Y001), the National Science and Technology Infrastructure Programme (No. 2014BAC16B03), and the CMA Innovation Team for Haze-fog Observation and Forecasts.

\section{Reference:}

An, X.Q., Tao Y., Mi, S.Q., Sun, Z.B., Hou Q., 2015. Association between PM10 and Respiratory Hospital Admissions in Different Seasons in Lanzhou. J. Environ. Health, 77, 64-71.

Che, H.Z., Zhang, X.Y., Li, Y., Zhou, Z.J., Qu, J.J., Hao, X.J., 2009. Haze trends over the capital cities of 31 provinces in China, 1981-2005. Theoretical and Applied Climatology, 97, 235-242, doi: 10.1007/s00704-008-0059-8.

Chen, Z.H., Cheng, S.Y., Li, J.B., Guo, X.R., Wang, W.H., Chen, D.S., 2008. Relationship between atmospheric pollution processes and synoptic pressure patterns in northern China. Atmos. Environ., 42, 6078-6087, doi:10.1016/j.atmosenv.2008.03.043.

Chen, Y., Zhao, C. S., Zhang, Q., Deng, Z. Z., Huang, M. Y., and Ma, X. C., 2009. Aircraft study of Mountain Chimney Effect of Beijing, China. J. Geophys. Res., 114, D08306, doi:10.1029/2008JD010610.

Chen, H.P., Wang, H.J., 2015. Haze Days in North China and the associated atmospheric circulations based on daily visibility data from 1960 to 2012. J. Geophys. Res. Atmos., 120, 5895-5909, doi: 10.1002/2015JD023225.

Demuzere, M., Trigo, R.M., Vila-Guerau de Arellano, J., van Lipzig, N.P.M., 2009. The impact of 
weather and atmospheric circulation on $\mathrm{O}_{3}$ and $\mathrm{PM}_{10}$ levels at a rural mid-latitude site. Atmos. Chem. Phys., 9, 2695-2714.

Fu, G.Q., Xu, W.Y., Yang, R.F., Li, J.B., Zhao, C.S., 2014. The distribution and trends of fog and haze in the North China Plain over the past 30 years. Atmos. Chem. Phys., 14, 11949-11958. doi:10.5194/acp-14-11949-2014.

Guo, J., Deng, M., Lee, S.S., Wang, F., Li, Z., Zhai, P., Liu, H., Lv, W., Yao, W., Li X., 2016. Delaying precipitation and lightning by air pollution over the Pearl River Delta. Part I: Observational analyses, J. Geophys. Res. Atmos., 121, 6472-6488, doi:10.1002/2015JD023257.

He, J.J., Yu, Y., Xie, Y.C., Mao, H.J., Wu, L., Liu, N., Zhao, S.P., 2016a. Numerical model-based artificial neural network model and its application for quantifying impact factors of urban air quality. Water Air Soil Pollut., 227, 235, doi: 10.1007/s11270-016-2930-z.

He, J.J., Wu, L., Mao, H.J., Liu, H.L., Jing, B.Y., Yu, Y., Ren, P.P., Feng, C., Liu, X.H., $2016 b$. Development of a vehicle emission inventory with high temporal-spatial resolution based on NRT traffic data and its impact on air pollution in Beijing-Part 2: Impact of vehicle emission on urban air quality. Atmos. Chem. Phys., 16, 3171-3184, doi:10.5194/acp-16-3171-2016.

He, J.J., Gong, S.L., Yu, Y., Yu, L.J., Wu, L., Mao, H.J., Song, C.B., Zhao, S.P., Liu, H.L., Li, X.Y., Li, R.P., 2017a. Air pollution characteristics and their relationship to meteorological conditions during 2014-2015 in Chinese major cities. Environ. Pollut., 223, 484-496, doi: 10.1016/j.envpol.2017.01.050.

He, J.J., Gong, S.L., Liu, H.L., An, X.Q., Yu, Y., Zhao, S.P., Wu, L., Song, C.B., Zhou, C.H., Wang, J., Yin, C.M., Yu, L.J., 2017b. Influence of meteorological conditions on interannual variations of particle matter pollution during winter the Beijing-Tianjin-Hebei area. Journal of Meteorological Research, 31, 1062-1069, doi:10.1007/s13351-017-7039-9.

He, J.J., Mao, H.J., Gong, S.L., Yu, Y., Wu, L., Liu, H.L., Chen, Y., Jing, B.Y., Ren, P.P., Zou, C., 2017c. Investigation of particulate matter regional transport in Beijing based on numerical simulation. Aerosol and Air Quality Research, 17, 1181-1189, doi:10.4209/aaqr.2016.03.0110.

Huth, R., 1996. An intercomparison of computer-assisted circulations classification methods. Int. J. Climatol., 16, 893-922.

Jiang, N.B., Dirks, K.N., Luo, K., 2014. Effects of local, synoptic and large-scale climate conditions on daily nitrogen dioxide concentrations in Auckland, New Zealand. Int. J. Climatol., 34, 1883- 
1897, doi: 10.1002/joc.3808.

Jiang, N.B., Scorgie, Y., Hart, M., Riley, M.L., Crawford, J., Beggs, P.J., Edwards, G.C., Chang, L., Salter, D., Virgilio, G.D., 2017. Visualising the relationships between synoptic circulation type and air quality in Sydney, a subtropical coastal-basin environment. Int. J. Climatol., 37,12111228, doi: 10.1002/joc.4770.

Lee, C.C., Ballinger, T.J., Domino, N.A., 2012. Utilizing map pattern classification and surface weather typing to relate climate to the air quality index in Cleveland, Ohia. Atmos Environ, 63, 50-59, doi: 10.1016/j.atmosenv.2012.09.024.

Li, L.J., Wang, Y., Li, J.X., Xin, L.Z., Jin, J., 2012. The analysis of heavy air pollution in Beijing during 2000-2010. China Environmental Science, 32, 23-30 (in Chinese).

Liu, D., Gao, S.C., 2011. Determining the number of clusters in K-means clustering algorithm. Silicon Valley, 6, 38-39 (in Chinese).

Liu, T.T., Gong, S.L., He, J.J., Yu, M., Wang, Q.F., Li, H.R., Liu, W., Zhang, J., Li, L., Wang, X.G., Li, S.L., Lu, Y.L., Du, H.T., Wang, Y.Q., Zhou, C.H., Liu, H.L., Zhao, Q.C., 2017. Attributions of meteorological and emission factors to the 2015 winter severe haze pollution episodes in China’s Jing-Jin-Ji area. Atmos. Chem. Phys., 17, 2971-2980, doi:10.5194/acp-17-2971-2017.

Meng, Y.J., Cheng, C.L., 2002. Impact of surface synoptic situations on air pollution in Beijing area. Meteorological Monthly, 28, 42-47 (in Chinese).

Miao, Y.C., Guo, J.P., Liu, S.H., Liu, H., Li, Z.Q., Zhang, W.C., Zhai, P.M., 2017. Classification of summertime synoptic patterns in Beijing and their associations with boundary layer structure affecting aerosol pollution. Atmos. Chem. Phys., 17, 3097-3110, doi:10.5194/acp-17-3097-2017.

Oanh, N.T.K., Chutimon, P., Ekbordin, W., Supat, W., 2005. Meteorological pattern classification and application for forecasting air pollution episode potential in a mountain-valley area. Atmos Environ, 39, 1211-1225, doi: 10.1016/j.atmosenv.2004.10.015.

Pearce, J.L., Beringer, J., Nicholls, N., Hyndman, R.J., Uotila, P., Tapper, N.J., 2011. Investigating the influence of synoptic-scale meteorology on air quality using self-organizing maps and generalized additive modelling. Atmos. Environ., 45, 128-136, doi: 10.1016/j.atmosenv.2010.09.032.

Yang, Y., Liao, H., Lou, S.J., 2016. Increase in winter haze over eastern China in recent decades Roles of variations in meteorological parameters and anthropogenic emissions. J. Geophys. Res. 
Atmos., 121, 13050-13065, doi: 10.1002/2016JD025136.

447 Zhang, J.P., Zhu, T., Zhang, Q.H., Li, C.C., Shu, H.L., Ying, Y., Dai, Z.P., Wang, X., Liu, X.Y., Liang, 448 A.M., Shen, H.X., Yi, B.Q., 2012. The impact of circulation patterns on regional transport 449 pathways and air quality over Beijing and its surroundings. Atmos. Chem. Phys., 12, 5031-5053, 450 doi: 10.5194/acp-12-5031-2012.

451 Zhang, R.H., Li, Q., Zhang, R.N., 2014. Meteorological conditions for the persistent severe fog and 452 haze event over eastern China in January. Science China: Earth Sciences, 57, 26-35, doi: 10.1007/s11430-013-4774-3.

454 Zhang, X.Y., Sun, J.Y., Wang, Y.Q., Li, W.J., Zhang, Q., Wang, W.G., Quan, J.N., Cao, G.L., Wang, 455 J.Z., Yang, Y.Q., Zhang, Y.M., 2013. Factors contributing to haze and fog in China. Chin Sci 456 Bull, 58, 1178-1187, doi: 10.1360/972013-150 (in Chinese). 